\title{
The Ratio of L1 Influence in Pronunciation Errors of Business English Students
}

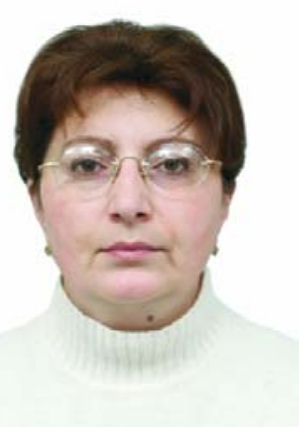

Amalia Babayan

\section{Introduction}

In a Business English classroom it is not a rare occasion to hear such utterances as / $f_{I}^{\prime}$ nansa/ for 'financier', /sab'saIdari/for 'subsidiary', /ser'vaIs/ for 'service', /I'kınэmik/ for 'economic', /eks'kjutrv/ for 'executive' and the like. The persistence and plethora of pronunciation errors present during the educational process has made us undertake a small-scale research to have a closer look into the problem. In this paper we would like to refer to the findings of the action research on the types of pronunciation errors and their occurrence among Armenian learners of Business English. The situation of having a great number of mispronounced words, to say nothing of the distorted rhythmic and intonation patterns of speech, calls for certain questions to ponder about:

- Why do students make so many pronunciation mistakes?

- What are the limits of promoting current pronunciation?

- How significant is the L1 impact?

- What should be done to cope with this situation?

However, before launching into the discussion of the issue it is essential to identify whether we are dealing with a problem worthwhile to consider. After all, business people all over the world manage to understand each other, 'they are confident, fluent communicators who get their messages across quickly and clearly' (Eustace, 2005) and actual business does not suffer from the fact that the word 'business' is pronounced /bIz'nes/. 'The driving force for the non-native speakers is getting information across efficiently' (Jenkins, 1996). But what is the role of correct pronunciation in securing this efficiency? Would it not be a waste of time to spot and correct the pronunciation errors in a BE classroom when there is so much language material to cover?

\section{Background to the study}

There have been different approaches to the 'general neglect of teaching pronunciation in contemporary language pedagogy’ (Wong, 1999). A.S. Bobda notes that 'among the innumerable deviations from native forms at the level of grammar, vocabulary and pronunciation... [pronunciation] exhibits the highest number of such deviations' (Bobda, 1991). However, many scholars (Kachru, 1986; Todd and Hancock, 1986; Pride, 1982; etc.) 'argue persuasively for the tolerance' of this state of things, speaking of English as a world language or referring to new Englishes, or difficulties of 
teaching pronunciation in the non-English-speaking environment, justifying it with the scarcity of books dedicated to pronunciation or limited help and guidance to find (Vaughan-Rees, 2006). It is estimated that 80 per cent of conversations in English worldwide do not involve a native speaker, and RP is used by no more than 3 per cent of native speakers. Nevertheless, J. Jenkins puts forward the teaching theory of the 'Common core', which limits the 'Common core' to the areas where pronunciation errors , mainly from L1 transfer should be eliminated, because they threaten... intelligibility, all other deviations being regarded not as "errors" but as acceptable regional differences on a par with features of L1 English regional accents (Jenkins, 1996). Call it a 'Common core' or by some other name, today scholars are unanimous on the issue of 'having intelligible speakers'(Wong, 1999), because 'listening comprehension breaks down not only when learners hear unfamiliar words but when they simply fail to recognize familiar words embedded in the stream of speech (Vaughan-Rees, 2006). A. S. Bobda quotes that 'one of the most dramatic reports on the intelligibility of non-native Englishes is from professor Honey (Honey, 1989), who reports that top-level managers, lawyers, engineers, and university teachers from former British colonies are facing serious problems of intelligibility in Britain nowadays in their professions' (Bobda, 1991).

G. Eustace, in the Business English professional section of ETP, is explicitly clear in his message: 'For many non-native speakers, accuracy may not be vitally important, but clarity of speech, to facilitate ease of understanding, certainly is'. He concludes that 'ignoring a lot of grammatical errors but aiming for standardized clear pronunciation may not be standard teaching practice. Some may well find it unpalatable. But there is a respectable argument for saying that teachers could be serving their business students best by adopting that approach' (Eustace, 2005).

Ellis and Johnson, in their prizewinner book of "Teaching Business English", while presenting the list of eight priorities of "what the majority of business learners need to acquire' include the entry of '- clear pronunciation and delivery': as simple as that. (Ellis \& Johnson, 1996).

The demand to 'treat language learning holistically' equally refers to the inclusion of teaching pronunciation, as 'focusing on meaning does not require ignoring forms' (Borg, 2004). When pronunciation teaching is not treated as an integral part of the entire educational process, it is an acknowledged fact that learner's intelligibility suffers significantly.

By 'teaching pronunciation' we mean teaching not only the sounds but the rhythmic patterns and, why not, intonation as well, for 'in the perception of speech a person identifies the rhythmic patterns relatively quicker, while individual characteristics of vowels and consonants of the utterance are discerned by him/her later (Vinarskaya \& Michourina, 1977). And it is during the teaching-learning process that the student learning the language in a non-English-speaking environment has the chance to grasp and drill the acoustic impact of the spoken language, which is crucial. Psychologists emphasize that 'acoustic patterns of a language are formed and fostered during the experience of verbal communication only, and, by far, not simultaneously' (Vinarskaya \& Michourina, 1977). 
Having cast away the doubts about the necessity of teaching pronunciation, we may assert that it is an issue to be addressed during the educational process, having in mind its general requirements, deviations and limitations. Paul Emmerson's 'mutual intelligibility' theory specifies the best criteria to adhere to. In his article "L3 and the new inner circle" he draws distinct boundaries of what is represented by "fully intelligible international English'. He identifies the latter as 'RP/GA Minus' with 'HighFrequency Lexis Plus' where ' 'RP/GA Minus' is any of individual's pronunciation where:

- words are spoken approximately as they are written in phonetic script in ELT dictionaries (RP or GA), but there is a slight accent according to the country of origin;

- there is use of tone units to create chunks of meaning and nuclear stress to make key words prominent;

- but there is not much use of assimilation/elision/weak forms' (Emmerson, 2006).

\section{Data collection}

Realizing how important correct pronunciation is for fluent and efficient business communication, and having witnessed the free and random phonetic 'interpretations' of words in class, we recorded and transcribed students' speech within a period of six semesters. The language proficiency of students ranged from lower intermediate to upper intermediate (from freshmen to graduate students). The observations were made discreetly, with no intrusions or interruptions of the free flow of the students' speech, though, certainly with their consent.

Our initial attempts to ask the students to make their current reports standing nearer to the tape-recorder, or to speak up to be recorded well, proved to be non-productive, as even the best students get frustrated from the awareness of being recorded openly and end up with unnatural, distinctly erroneous performance. Consequently, we changed the method of data collecting, starting to obtain it through the recordings of volunteers (fortunately there are sporty young people), our feedback notes and by transcribing short sessions on pronunciation focus, which we have tried to make a part of our lessons.

\section{Research and findings}

For our present analysis we have chosen sound and stress errors, which, in many cases, are interconnected and stand out as both minor and more significant barriers in the process of delivering intelligible speech. After a close survey of the data obtained, we have classified the most common pronunciation errors into several groups and subgroups, according to the frequency and quality of their occurrence.

1. The largest of them is the mother tongue or L1 influence group, where there is also a niche for the subgroup of international words. The L1 influence or transfer is exposed in different ways. We shall illustrate them with typical examples taken from the bank of errors. 
- The largest group of errors reflects the students' approach to read every single letter of the word, which is, actually an application of the Armenian or Russian alphabetic reading mode. Words like 'debt', 'liable' or 'legal' are read as /debt/, /l' $\mathrm{abl} /$ or /le'gal/.

- The mother tongue alphabetic reading and the use of only one stressed syllable in a word (one of the features of the Armenian language) affects the pronunciation of prefixes as well, with the effect of neglecting or minimizing their morphological meaning. For example, in the mispronounced word /rein'vestrd/ the sound /e/ in the prefix instead of $/ i$ / and one stress only deprive the prefix 're-' of its full meaning. The same is the case with the words /ks'svner/ - 'co-owner' or /kardi'neitar/ - 'coordinator'.

- The tendency of L1 type reading mode is particularly present in the pronunciation of borrowed or international words, which have come into Armenian mainly via the Russian language Therefore, in such words as /Izolertid/ - 'isolated', /klient/ - 'client', /final/ - 'final', /firm/ - firm', /fi'nansiz/ - 'finances', /a'gensi/ 'agency', /ritual/- 'ritual' and the like, the strong influence of Armenian or Russian is evident.

However, the word 'company' stands out separately, with the wrong pronunciation of / kompani/, though in Russian (the variant used by many Armenians in their everyday speech) it sounds as /,kam'paniya/. 99 per cent of first-time readers choose $/ \rho /$ instead of $/ \alpha /$, presumably applying the $\mathrm{L} 1$ alphabetic reading method, seeing this word as a detached from Russian, foreign language entity.

- Alongside with faulty pronunciation, the transfer of the end-of-word Armenian fixed stress onto the English words is quite common. Some examples are /pra'dukt/ - 'product', /bar'ter/ - 'barter', /bIz'nes/ - 'business' or /,dive'lops/ 'develops', /karpa'reit/ - 'corporate', /par'tfers/ - 'purchase', /kanva'seIfn/ 'conversation', etc. .

- We also detect a transfer of L1 dialect stress. Examples are not rare. Let us bring one of them: the word /me'morandam/ for 'memorandum' reflects the stress of the north-western dialect of the Armenian language.

- Another subgroup of L1 related errors involves the host of those borrowed words that have the sounds $/ \mathrm{kh} /$ and $/ \mathrm{ts} /$. Owing to the lack of these sounds in the English language, these words use $/ \mathbf{k} /$ and $/ \mathbf{s} /$ respectively. However, students tend to rely on their mother tongue variation of the borrowed words, which had successfully incorporated the original sounds of $/ \mathrm{kh} /$ and $/ \mathrm{ts} /$ of such words. Thus, they are quite at ease with $/ j a \mathrm{kht} /$ or /tekh'nIks/or / sotsial/ or /protses/ - or /dIstsIplin/.

- In a similar, though reverse way, students ignore the sounds which are absent in the Armenian language. This particularly refers to the pronunciation of diphthongs and the sounds $/ \mathfrak{x} /, / w /, / \theta /$ and $/ \delta /$, which are $\operatorname{read} / a, e /, / v /, / d, t /$ and $/ z /$ respectively. Students say /a'verr/ - 'aware' instead of /a'wea/ (In this single word we can see a 'w-v' and ' $\varepsilon \partial$ - eI' shift), /ovanə/ - 'owner' instead of / $\partial u n \partial /$,

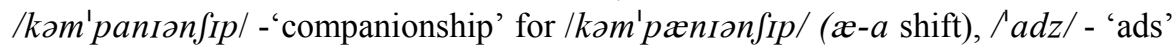


for /'ædz/, /^də/ - 'other' for /'^ðə/and so on. The tendency is towards simplification of the pronunciation, which often results in one sound only.

- An interesting impact of L1 can be seen in the phenomenon of associative articulation, which can presumably be explained by subliminal processes. One example of this is the collocation 'gas mileage' which was successfully read as /gais mi'la:d3/. We dare to assume that it may be caused by drawing up certain association with the L1 word 'uhpud'. Such examples are not few and far between.

2. The second large group covers the errors which are rooted in the prior knowledge of English. Having learnt some of the pronunciation rules of this or that letter or letter-combination, many students assume that they should sound in the same way in every position. This attitude is partly due to the poor knowledge of the pronunciation rules, or may be seen as an expression of associative approach, or can also be explained by the automatic reaction of students.

- The logic behind is as follows: If in the word 'teacher' 'ea' is /i:/, why should it not be /i:/ in 'greater' / grista/ or 'measurement' / mi:zarmant/ or 'threat' / Ori:t/;

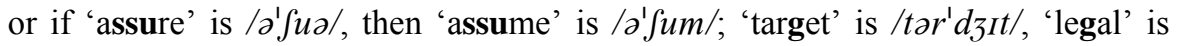
Mlidzal/ and 'exposure' is /ekspofuz/ like 'sure'. If 'mine' is /maIn/, then all should be normal with /detarmain/ or /promais/. Another vivid example is the pronunciation of 'ai': if 'ai' is /eI/ like in 'gain', then it is all right with /bor'geınıl/ - 'bargaining' or /kəp'tern/ - 'captain'. Following the same logic, students are equally happy with /servais/ - 'service' and /sab'saIdari/ 'subsidiary' (open syllable pronunciation rule).

- However, when students do not know the rules specifying the pronunciation of certain words or are unaware of their real sounding, they pick up whatever they can. The tortured word 'society' is pronounced with either $/ k /$ or $/ \int /$ for the letter 'c' and $/ I \partial /, / I /$ or $/ i$ 'eI/ for the letter-combination 'ie' /sskiati/, /sofitil, /sofi'erti/, etc. .

- There are cases when students suspect that a familiar letter-combination should be pronounced somewhat differently and they either hit the point or miss it. A typical case is the pronunciation of 'ea': in the word 'increase' this suspicion has brought about a modified, wrong variant of $/ \mathrm{In}^{\prime} \mathrm{kres} /$.

3. The next set of pronunciation errors reflects the overlapping of the pronunciation of derivatives. When the student knows the pronunciation of a certain word, he relays it on to its derivatives, often with a faulty result; e.g. 'significant' is pronounced /saI'nIfIkant/: the impact of the word 'sign' is evident, or one can often hear /priffarabl/ for preferable or /luzis/ for losses.

The words 'economy', 'economic' and 'economist' are the most 'unlucky' group of derivatives with Business English students. They are exceptionally rich in wrong pronunciation variants: leka'nomi/, /e'konəmik/, /ekonomik/, /ıka'nomist/, 
$/ I^{\prime} k$ onomiks/. If students do not learn the correct pronunciation, they are lost in guesses or indulge in their own interpretations.

4. Another noteworthy observation is the following: students tend to stress the very part of the word which is already familiar to them. In the mispronounced word 'surpluses'- /sar'plasiz/ it is evident that the student derives the stress from the prior knowledge of the word 'plus'.

5. Still another group of mispronounced words is associated with the noun-verb stress shift. It is a common error when students shift the stress of the more frequently used verb-stress on to the corresponding noun: e.g. the nouns 'transfers and 'project' are mostly read as /trans'forz/ and /pra'dzekt/.

6. There are minor cases as well, that deserve attention. One of them refers to the wrong pronunciation of voiceless and voiced consonants. The most common is the $/ \theta-\delta /$ pair. The occurrence of $/ \theta /$ instead of $/ ð /$ is prevailing. A good example of it is $/ \supset l^{\prime} \theta o v /$ for 'although'.

The letter-combination 'qu', too, poses some problems. If not taught beforehand, students read the letter 'u' separately as /ju/, resulting in /I' $k j u \partial l i /$ - 'equally'.

7. Still, another type of errors, 'chain-errors' we may call them, is caused by the application of a wrong stress, which inevitably calls for a distortion in the pronunciation of the word. Had the student put the stress in the right place, no chain reaction would have been possible, or the pronunciation faults would have been marginal only. For example, if in the word /a'plikabl/ - 'applicable' the first syllable were stressed, there would be a slight deviation from the norm only. The same stands true for the words /monopolist/ - 'monopolist' or /proprital 'proprietor'.

8. A decent number of errors are born from the students' urge to stylize or make the words 'user-friendly'. Such words might even seem 'elegant' to some learners'. Still, such utterances are wrong. For example, 'transfers' are /trans'fiars/, 'executive' is /eks'kjutrv/, 'economic' is /,eka'nImIk/, etc..

Another sample of 'stylish' pronunciation is connected with the distorted perception of the glottal stop $/ \% /$, which is a far cry from the Armenian $/ \mathrm{w} /$. Students savour uttering /argani'zeifn/ for 'organization' or /Intra'djusd/ for 'introduced' or /I'kanomik/ for 'economic'. Certainly, the background of these errors is the lack of appropriate knowledge.

9. An interesting example is / $k \partial^{\prime} m o n /$ for 'common', which reflects the subliminal influence of everyday words from songs and films. 
10. Eventually, there are many other examples of pronunciation errors that do not fall under any of the groupings. Sometimes students tend to tackle words quite freely, choosing the stress at their convenience: for example /spesifik/ - 'specific', `oltarnertrvz/ - 'alternatives', / konsjumarz/ - 'consumers', etc..

\section{Conclusion}

The findings of the action research have revealed that a substantial portion of pronunciation errors are closely related to the influence of the Armenian language and may be grouped according to the type of error. The significant impact of L1 affects not only the pronunciation of sounds but the choice of stress as well, which, in most cases, causes distortion of the rhythmic patterns of words. This finding comes to prove, in the context of Armenian L1 environment, the statement of the prominent Japanese scholar Tsunoda that 'the native language differentiates the person's perception, acquisition, his feel and understanding of the sounds that come from the surrounding milieu. The native tongue is closely connected with the development of the emotional mechanisms in the brain. I assume that the native language, which is acquired in childhood, has its greatest impact on shaping the unique cultural and psychological pattern of every ethnic group' (Tsunoda, 1982).

The second large group of errors indicates how differently the already acquired knowledge of English can influence the acquisition of the new language material in respect of pronunciation. And only a relatively small number of pronunciation errors bear the character of individual interpretations.

These findings could enable us to develop appropriate strategies in the process of teaching Business English, by incorporating certain pronunciation-focused approaches at different stages of the course, with the aim of bringing to a possible minimum point the occurrence of pronunciation errors.

\section{References:}

1. Bobda A. Does Pronunciation Matter? // English Teaching Forum. Vol.29, 1991. No. 4.

2. Borg E. The ABC of ELT... 'CBI'. IATEFL Issues, 181, 2004.

3. Emmerson P. . L3 and the New Inner Circle. IATEFL Issues, 189, 2006.

4. Ellis M. \& Johnson C. Teaching Business English. Oxford: Oxford University Press, 1996.

5. Eustace G. Content Versus Context. // English Teaching Professional, 41, 2005.

6. Honey J. Does Accent Matter? London: Faber and Faber, 1989.

7. Kachru B. The Other Tongue. Oxford: Pergamon Press, 1983.

8. Pride J. (ed.). New Englishes. Rowley, Mass.: Newsbury House, 1982.

9. Todd L. \& Hancock I. International English Usage. London: Croom Helm, 1986. 
10. Tsunoda T. The Mother Tongue and the Brain. // UNESCO Curier, March issue (Rus.), 1982.

11. Vaughan-Rees M. Looking Back, Moving Forward. // English Teaching Professional, 43, 2006.

12. Vinarskaya E. \& Michurina K. Acoustic Self-Control in the Process of Oral Communication. // (eds.) Feygenberd I. \& Zhuravlyova G. Relative Prognosis in the Activity of a Person (Rus.). Moscow: Nauka, 1977.

13. Wong R. Pronunciation Myths and Facts. // K. Thomas (ed.). Teacher Development: Making the Right Moves. Washington: US Department of State, 1999.

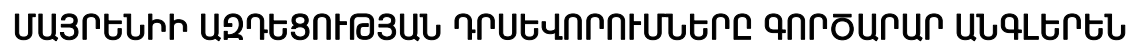

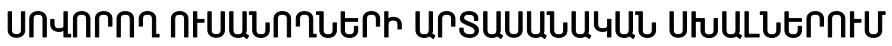

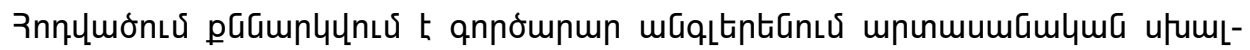

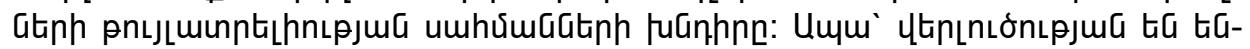

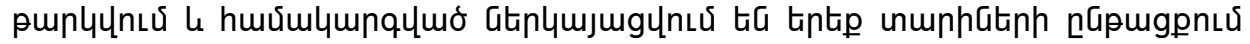

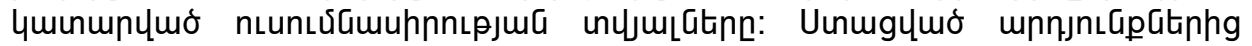

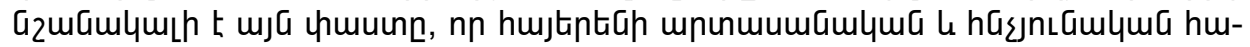

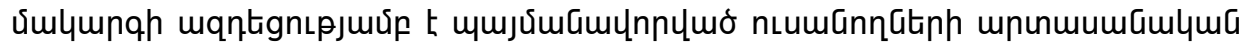
ulumiGitiph qtinuly2hn úmun: 